\title{
Características físicas e tecnológicas de pães elaborados com farelo de arroz torrado
}

\section{Technological and physical characteristics of breads made with toasted rice meal}

\author{
Manoel Soares Soares Júnior ${ }^{*}$; Priscila Zaczuk Bassinello²; Diracy Betânia \\ Cavalcante Lemos Lacerda ${ }^{3}$ Selma Nakamoto Koakuzu${ }^{4}$; Pedro Francisco \\ Cavalcante Gebin ${ }^{5}$; Thaís de Lima Junqueira ${ }^{5}$; Vinícius Almeida Gomes ${ }^{5}$
}

\section{Resumo}

O objetivo desse trabalho foi avaliar a qualidade física e sensorial de pães de forma elaborados com diferentes níveis de substituição de farinha de trigo (FT) por farelo de arroz torrado (FAT). Determinouse a composição centesimal, incluindo os teores de fibra alimentar solúvel, insolúvel e total do FAT. Utilizou-se delineamento inteiramente casualisado, com cinco tratamentos $(0,0 \%, 7,5 \%, 15,0 \%, 22,5 \%$ e 30,0\% de substituição de FT por FAT) em três repetições. Foram avaliados a cor e os escores do teste de panificação de cada tratamento. No tratamento com FAT que obteve o maior escore total no teste de panificação, foram realizadas análises microbiológicas. Ocorreram escurecimento e diminuição do volume específico gradativo dos pães à medida que se adicionou maior quantidade de FAT, devido ao elevado teor de fibra alimentar total do FAT $(29,2 \%)$, que aumentou a retenção de umidade no produto final. Entre os tratamentos com FAT, o pão com 7,5\% de substituição de FT por FAT obteve o maior escore no teste de panificação $(83,5)$, somente diferindo $(\mathrm{P} \leq 0,05)$ do tratamento controle em relação ao volume específico e escore total, estando adequado em relação aos padrões legais de Salmonella sp, coliforme total e de bolores e leveduras, podendo ser recomendado para comercialização.

Palavras-chave: Oryza sativa L., subproduto, desenvolvimento de produtos

\begin{abstract}
The aim of this work was to evaluate the physical and sensory quality of form breads type formulated with different levels of substitution of wheat flour (FT) by toasted rice bran (FAT). It was determined the centesimal composition, including the soluble and insoluble dietary fiber contents. It was applied whole randomized design with five treatments $(0.0 \%, 7.5 \%, 15.0 \%, 22.5 \%$ and $30.0 \%$ of FAT in substitution to FT) and three repetitions. The color and the breadmaking test scores were evaluated for each treatment. Microbiological analyses were done to the treatment with FAT which reached the highest total score. The higher substitution level of FT by FAT, darker and lower specific volume of breads, because of the high level of dietary fiber content of FAT $(29,2 \%)$, what increased the moisture retention in the final product. Among the treatments containing FAT, the bread with $7.5 \%$ of FAT had the highest score at the breadmaking test $(83.5)$, which differed $(\mathrm{P}<0.05)$ from control treatment only for specific volume and total score parameters, presenting an adequate profile for Salmonella sp, total coliforms, moldiness and yeast in relation to legislation limits, and so it can be recommended for commercialization.
\end{abstract}

Key words: Oryza sativa L., byproduct, products development

1 Prof. Adjunto da Escola de Agronomia e Engenharia de Alimentos da UFG. E-mail: manoel@agro.ufg.br.

Pesquisadora da Embrapa Arroz e Feijão.

Aluna de Mestrado do Programa de Pós-Graduação em Ciência e Tecnologia de Alimentos da UFG.

4 Técnica de nível superior da Embrapa Arroz e Feijão.

5 Alunos de Graduação em Engenharia de Alimentos da UFG.

Autor para correspondência 


\section{Introdução}

O arroz (Oryza sativa L.) é uma das plantas cultivadas mais antigas no mundo. No âmbito mundial, o Brasil, apesar de ocupar a décima posição em volume de produção (11.000.000 ton.), encontra-se muito aquém dos maiores produtores, como China (200.000.000 ton.), Índia (132.000.000 ton.) e Indonésia (50.000.000 ton.) (SAMPAIO; MEDEIROS, 2006). O arroz assumiu grande importância social, econômica e política desde os tempos coloniais, alcançando o país a condição de maior produtor no hemisfério ocidental (PEREIRA, 2002).

O arroz é um cereal constituído por diferentes tecidos, com estrutura, composição química e funções bastante diferenciadas, que é consumido como grão inteiro polido (VIEIRA; SANTOS; SANT'ANA, 1999). Para obtenção do produto beneficiado polido, o arroz é primeiramente submetido ao descascamento do grão. A casca representa aproximadamente 20 a $22 \%$ do peso total. O grão descascado integral passa pelas etapas de brunição e polimento, quando são retirados o embrião (total ou parcialmente) e a maior parte da película que recobre o grão. A brunição, também conhecida como branqueamento, é complementada pelo polimento, que consiste no acabamento do produto e remoção dos resíduos de farelo. O coproduto resultante constitui o farelo, que representa cerca de $8 \%$ do grão em casca ou $10 \%$ do produto descascado (CASTRO et al., 1999).

Nas regiões onde o arroz é altamente consumido, grandes quantidades de farelo de arroz são desprezadas, em função da falta de controle sanitário no beneficiamento e da fácil rancificação do produto, que restringem a sua utilização na alimentação humana. A aplicação do calor é o método mais seguro e eficiente para manter sua qualidade e alto valor industrial, uma vez que as enzimas, os microrganismos, os insetos e os agentes tóxicos naturais no farelo são termicamente lábeis (SILVA; SANCHES; AMANTE, 2006). Para ser estabilizado, o farelo de arroz pode ser torrado a temperaturas na faixa de $105-110^{\circ} \mathrm{C}$ (ALENCAR; ALVARENGA, 1991).

O farelo de arroz é uma excelente fonte de fibras, vitaminas, minerais, proteínas e lipídeos. As fibras do farelo de arroz são componentes que possuem boa capacidade de absorção de água e óleo e por isso podem contribuir para o desenvolvimento de uma enorme variedade de produtos industrializados que requerem estas propriedades (SAUNDERS, 1990). Estas fibras são do tipo insolúvel, como hemiceluloses e lignina, consideradas importantes na prevenção do câncer de cólon. A fração de fibras insolúveis possui propriedades importantes, que incluem a capacidade de reter água, aumentar o volume fecal, diluir substâncias carcinogênicas presentes no conteúdo do intestino grosso, reduzir o tempo de trânsito no cólon e o contato entre os carcinógenos (DIAS et al., 1994).

As composições químicas dos farelos de arroz in natura e torrado não apresentam diferenças significativas entre si, exceto em relação à umidade e aos lipídeos (ALENCAR; ALVARENGA, 1991). $\mathrm{O}$ farelo de arroz apresenta propriedades únicas quando comparado a outros farelos de cereais, quanto ao seu emprego em panificação é apropriado para elaboração de diversos produtos, como pães, muffins, bolos, biscoitos e tortas (SAUNDERS, 1990). Entretanto, na literatura científica há poucos estudos sobre as aplicações do farelo de arroz em produtos para a alimentação humana (CARVALHO, 1995; HOFFPAUER, 2005).

O pão é um alimento básico e, atualmente, são poucos os países do mundo onde não se fabrica ou não se consome pão. Os produtos de panificação evoluíram até adquirir muitas formas, cada uma com características bastante diferentes que as distingue uma das outras. Através dos séculos, os mais experientes padeiros do mundo desenvolveram novas variedades de pão, aplicando os conhecimentos adquiridos acerca de como utilizar de forma mais eficaz as matérias primas disponíveis para conseguir 
a qualidade de pão desejada (CAUVAIN; YOUNG, 2002).

Os objetivos deste trabalho foram determinar a composição centesimal, teores de fibra alimentar total, solúvel e insolúvel do farelo de arroz torrado, avaliar a qualidade tecnológica de pães de forma formulados com diferentes níveis de substituição da FT por FAT e ainda verificar a qualidade microbiológica quanto aos padrões de Salmonella sp, coliformes totais e bolores e leveduras do tratamento com as melhores características tecnológicas determinadas pelo teste de panificação.

\section{Material e Métodos}

Este estudo foi realizado nos Laboratórios de Panificação e de Análises Microbiológicas de Alimentos (Escola de Agronomia e Engenharia de Alimentos da UFG, Goiânia-GO) e de Tecnologia de Alimentos (Embrapa Arroz e Feijão, Santo Antônio de Goiás-GO). O farelo de arroz foi doado pela empresa Cristal Alimentos Ltda., localizada no Município de Aparecida de Goiânia, GO. Os demais ingredientes utilizados na formulação dos pães (farinha de trigo especial Lunar, leite em pó Leite Bom, sal comum Nevado, açúcar cristal Sabor Cristal, melhorador para farinhas e anti-mofo Itaiquara, margarina com 65\% lipídios Delícia e fermento fresco Fleischmann) foram adquiridos no comércio local de Goiânia-GO.

O farelo de arroz foi torrado no mesmo dia em que foi obtido, em bateladas de $500 \mathrm{~g}$ utilizandose panela em fogo direto, a uma temperatura aproximada de $110^{\circ} \mathrm{C}$ por $10 \mathrm{~min}$., e em seguida peneirado, conforme método descrito por Alencar e Alvarenga (1991). Após seu tratamento, o farelo foi embalado a vácuo, em saco laminado (polietileno/ nylon/polietileno) e armazenado à temperatura de $-18{ }^{\circ} \mathrm{C}$.

Os teores de umidade, proteínas, lipídios e cinzas do farelo de arroz torrado (FAT) foram determinados segundo as normas descritas pelo Instituto Adolfo
Lutz (BRASIL, 2005a): o teor de umidade em estufa a $105^{\circ} \mathrm{C}$ até peso constante, o nitrogênio pelo método de microKjeldahl e convertido em proteína bruta pelo fator 5,95 (ALENCAR; ALVARENGA, 1991), as cinzas por incineração em mufla a 550 ${ }^{\circ} \mathrm{C}$, os lipídios por extração direta em Soxhlet. As fibras alimentares solúvel, insolúvel e total foram determinadas por método enzímico-gravimétrico, baseado no método oficial n. ${ }^{0} \quad 985.29$ da ASSOCIATION OF OFFICIAL AGRICULTURAL CHEMISTS INTERNATIONAL - AOAC (1997). Os carboidratos totais foram calculados por diferença, subtraindo-se de 100 os valores encontrados para proteína, lipídios, fibra alimentar total e cinzas. O valor calórico total foi calculado multiplicando-se as porcentagens de lipídios, proteínas e carboidratos de cada amostra pelos seus valores calóricos respectivos: $9 \mathrm{kcal}, 4 \mathrm{kcal}$ e $4 \mathrm{kcal}$ - fatores de conversão de Atwater, segundo Merril e Watt apud Wilson, Santos e Vieira (1982). Todas as análises físico-químicas foram realizadas em triplicata. Os resultados foram avaliados calculando-se as médias, desvios-padrão e coeficientes de variação.

Para o desenvolvimento dos pães utilizou-se delineamento inteiramente casualisado (DIC), com cinco tratamentos (controle ou 0,0\%, 7,5\%, 15,0\%, $22,5 \%$ e $30,0 \%$ de substituição de farinha de trigo(FT) por FAT) e três repetições. O tratamento controle foi formulado com $3.000 \mathrm{~g}$ de FT e sem FAT, enquanto que os demais, na ordem anteriormente apresentada, utilizaram $2.775 \mathrm{~g}$ e $225 \mathrm{~g}, 2.550 \mathrm{~g}$ e $450 \mathrm{~g}, 2.325 \mathrm{~g}$ e $675 \mathrm{~g}, 2.100 \mathrm{~g}$ e $900 \mathrm{~g}$ de FT e FAT, respectivamente. Os demais ingredientes permaneceram constantes: sal (60 g), açúcar (180 g), fermento (150 g), margarina $(120 \mathrm{~g})$, leite em pó (60 g), melhorador (12 g) e anti-mofo (4 g). Utilizou-se água gelada, suficiente para dar o ponto de véu à massa. Os pães foram preparados utilizando ingredientes do mesmo lote de fabricação. Para o processamento dos pães utilizouse o método de panificação direta, padronizando-se os seguintes procedimentos: mistura e amassamento por 25 a 30 min em batedeira Superfecta (modelo BT-20), divisão e pesagem manual da massa (700 
g), moldagem manual, fermentação por $1 \mathrm{~h}$ e $45 \mathrm{~min}$ e cozimento em forno de lastro Superfecta, modelo $\mathrm{SC}-23$, por 45 minutos à temperatura de $160 \pm 5^{\circ} \mathrm{C}$.

A luninosidade $\left(\mathrm{L}^{*}\right)$ e as coordenadas de cromaticidade $\left(a^{*}\right.$ e $\left.b^{*}\right)$ de cada tratamento foram determinadas com o auxílio de um colorímetro Hunter-Lab (WHAT..., 2007). Os dados médios (10 replicatas) do volume específico e das variáveis de cor foram avaliados por análise de variância, sendo as médias dos resultados comparadas pelo teste Tukey a $5 \%$ de probabilidade (PIMENTELGOMES, 2000).

Uma equipe constituída por três indivíduos foi treinada para reconhecimento dos atributos e das escalas de avaliação numérica de cada uma das características estudadas no teste de panificação. Para a avaliação dos diferentes tratamentos atribuiuse escores para cada característica, a fim de totalizar uma pontuação máxima de 100. Avaliaram-se as características externas e internas, o aroma e o gosto, totalizando um escore geral para os pães de cada repetição, conforme descrito em Soares Júnior et al. (2006), com modificações. Para obtenção do escore para o volume específico, os valores médios obtidos foram multiplicados por 4,52, ao invés de 3,33 , com o objetivo de o tratamento controle obter escore máximo. A determinação dos escores dos tratamentos teve como referência para comparação o tratamento controle (escore máximo de 100 para todos os atributos). Os resultados do teste de panificação, com exceção do escore para volume específico, foram analisados por meio da estatística não paramétrica (teste Friedman e teste de comparação de médias de ensaios inteiramente casualizados).

O tratamento que obteve o maior escore geral médio entre os tratamentos com inclusão de FAT foi avaliado em relação à contagem de unidades formadoras de colônias (UFC) de coliformes totais e bolores e leveduras e presença ou ausência de Salmonella sp. Estas análises foram realizadas de acordo com os métodos citados na Instrução Normativa $\mathrm{n}^{\mathrm{o}}$. 62, de 26 de Agosto de 2003, do Ministério da Agricultura (BRASIL, 2003).

\section{Resultados e Discussão}

A composição centesimal média e o valor energético do farelo de arroz torrado (FAT), assim como os respectivos desvio-padrão e coeficiente de variação estão apresentados na Tabela 1. Segundo Vilas Boas (1999), a composição centesimal de um produto exprime, mesmo que seja de forma grosseira, o seu valor nutricional.

Tabela 1. Composição centesimal média, incluindo fibra alimentar solúvel, insolúvel e total, e valor calórico do farelo de arroz torrado (FAT) com seus respectivos desvio-padrão e coeficiente de variação

\begin{tabular}{lc}
\hline Característica & Média + desvio padrão (Coeficiente de Variação) \\
\hline Umidade $^{1}$ & $0,8 \pm 0,07(9,18)$ \\
Cinzas $^{1}$ & $10,2 \pm 0,13(1,27)$ \\
Proteínas $^{1}$ & $12,8 \pm 0,92(7,21)$ \\
Lipídios $^{1}$ & $20,5 \pm 0,16(0,79)$ \\
Carboidratos $^{1}$ & $26,5 \pm 1,78(6,72)$ \\
Fibra alimentar insolúvel $^{1}$ & $28,2 \pm 0,68(2,42)$ \\
Fibra alimentar solúvel $^{1}$ & $1,1 \pm 0,20(13,47)$ \\
Fibra alimentar total $^{1}$ & $29,2 \pm 0,86(2,95)$ \\
\hline Valor calórico $^{2}$ & $341,7 \pm 4,61(1,35)$ \\
${ }^{1}{ }^{2}(100 \mathrm{~g})^{-1}$ & \\
${ }^{2} \mathrm{kcal}(100 \mathrm{~g})^{-1}$ &
\end{tabular}


Os teores de umidade $\left[0,8 \mathrm{~g}(100 \mathrm{~g})^{-1}\right]$ e de cinzas $\left[10,2 \mathrm{~g}(100 \mathrm{~g})^{-1}\right]$ do FAT foram inferiores e superiores, respectivamente, aos determinados por Alencar e Alvarenga (1991) de 2,1 g (100 g) $)^{-1}$ e $9,3 \mathrm{~g}(100 \mathrm{~g})^{-1}$, respectivamente. A determinação da umidade constitui uma das medidas mais importantes utilizadas na análise de alimentos, uma vez que a quantidade de água presente nos alimentos está diretamente relacionada à sua estabilidade, qualidade e composição. O conteúdo de cinzas de um alimento expressa o resíduo inorgânico que permanece após a queima da matéria orgânica. $\mathrm{O}$ farelo de arroz possui quantidade significativa de minerais (fósforo, magnésio, potássio, ferro, manganês e zinco) (CARVALHO; BASSINELO, 2006; HOFFPAUER, 2005; SAUNDERS, 1990).

Existem fatores antinutricionais presentes no farelo de arroz, como a fitina, o inibidor de tripsina e a hemaglutinina (lectina). A maioria destes fatores é degradada pelo calor, com exceção da fitina. $\mathrm{O}$ ácido fítico (myo-inositol 1,2,3,4,5,6-hexafosfato, IP6) está presente em todo o reino vegetal e forma juntamente com os fosfatos, sais insolúveis com ferro, cálcio, zinco e magnésio, levando-os a compostos biologicamente inativos, sendo por isso denominado antinutriente. O grau de ação inibitória dos inositol fosfatos na absorção mineral depende do grau de fosforilação (LÖNNERDAL et al., 1989; BRUNE et al., 1992; HAN et al., 1994). Além disso, forma complexos com proteínas, tornandoas menos solúveis e mais resistentes à digestão proteolítica (CARVALHO, 1995). O grau em que a absorção mineral é prejudicada vai depender tanto da relativa concentração de ácido fítico e do mineral como também da força da ligação (RICKARD; THOMPSON, 1997). Porém, a literatura menciona que o ácido fitico em baixas concentrações apresenta efeitos positivos sobre a saúde como ação protetora frente ao câncer, e prevenção de enfermidades cardiovasculares (SHAHIDI, 1997; MARTINEZDOMINGUEZ; GOMES; LÉON, 2002). Além disso, o ácido fítico diminui a velocidade da digestão do amido. Ao retardar a digestão deste, amido mal absorvido pode chegar ao cólon e ser fermentado pela flora bacteriana produzindo-se ácidos graxos de cadeia curta (acetato, propionato e butirato) com atividade protetora contra o câncer que também ocasionam diminuição do $\mathrm{pH}$, que é considerada protetora frente aos agentes cancerígenos como ácidos biliares e amônio, que podem ser insolubilizados ou neutralizados respectivamente (RICKARD; THOMPSON, 1997).

Os teores médios de proteínas e lipídeos encontrados foram respectivamente de $12,8 \mathrm{~g}$ $\left(100 \mathrm{~g}^{-1}\right.$ e $20,5 \mathrm{~g}(100 \mathrm{~g})^{-1}$, sendo inferiores aos verificados por Alencar e Alvarenga (1991) de 14,2 $\mathrm{g}(100 \mathrm{~g})^{-1}$ e $21,5 \mathrm{~g}(100 \mathrm{~g})^{-1}$, respectivamente. A proteína do FAT é de boa qualidade. Uma análise dos aminoácidos da proteína do farelo de arroz revela a presença de todos os aminoácidos essenciais para o homem. A digestibilidade da proteína do farelo encontra-se em torno de 70-75\%. Outra vantagem da proteína do farelo de arroz é a ausência de efeitos indesejáveis em indivíduos intolerantes ou alérgicos ao glúten. A sua utilização tem também apresentado bons resultados como condicionador de massas em produtos de panificação, melhorando a retenção de gás, as propriedades de mistura e retardando a queda da massa após a fermentação (CARVALHO; BASSINELLO, 2006).

Entre os principais benefícios do uso do farelo à saúde, tem-se o teor de fibra alimentar, que atua na diminuição dos riscos de doenças cardíacas por meio da diminuição do colesterol ruim (LDL), e pela presença de insaponificáveis na fração lipídica bioativa. A fração lipídica do farelo de arroz possui alto nível de substâncias com valor nutracêutico, tais como o $\gamma$-orizanol (éster do ácido felúrico com álcoois triterpenóides), os tocoferóis e os tocotrienóis, os quais têm sido citados como poderosos agentes antioxidantes e eficientes na prevenção de doenças degenerativas.

Os teores de fibra alimentar total, solúvel e insolúvel obtidos neste trabalho foram 29,2 g (100 $\mathrm{g})^{-1}, 1,1 \mathrm{~g}(100 \mathrm{~g})^{-1} \mathrm{e} 28,2 \mathrm{~g}(100 \mathrm{~g})^{-1}$, respectivamente. 
Portanto, superiores aos observados por Saunders (1990) para fibra alimentar total [20-25 $\left.\mathrm{g}(100 \mathrm{~g})^{-1}\right] \mathrm{e}$ para fibra alimentar insolúvel $\left[18,4-23,2 \mathrm{~g}(100 \mathrm{~g})^{-1}\right]$, e inferiores para fibra alimentar solúvel de 1,6-1,8 g $(100 \mathrm{~g})^{-1}$. O farelo de arroz possui em sua composição alta quantidade de fibras do tipo insolúvel como hemiceluloses e lignina, consideradas importantes na prevenção do câncer de cólon. A fração de fibras insolúveis possui propriedades importantes, que incluem a capacidade de reter água, aumentar o volume fecal, diluir substâncias carcinogênicas presentes no conteúdo do intestino grosso, reduzir o tempo de trânsito no cólon e o contato entre os carcinógenos (DIAS et al., 1994).

O teor médio de carboidratos disponíveis e a energia do FAT obtidos neste trabalho foram de 26,5 $\mathrm{g}(100 \mathrm{~g})^{-1}$ e $341,7 \mathrm{kcal}(100 \mathrm{~g})^{-1}$, muito semelhante aos valores de $26,1 \mathrm{~g}(100 \mathrm{~g})^{-1}$ e $354,9 \mathrm{kcal}(100 \mathrm{~g})^{-1}$ obtidos por Alencar e Alvarenga (1991). Os dados publicados sobre a composição do farelo de arroz revelam larga faixa de variação de nutrientes, já que sua composição química depende de fatores associados à variedade e aspectos agronômicos, bem como ao processo de beneficiamento (BARBER; BARBER; MARTÍNEZ, 1981).
De acordo com a Tabela de Composição de Alimentos da USP (UNIVERSIDADE DE SÃO PAULO - USP, 2005), a farinha de trigo (FT) possui a seguinte composição centesimal: umidade $10,52 \mathrm{~g}$ $(100 \mathrm{~g})^{-1}$, fibra alimentar $2,82 \mathrm{~g}(100 \mathrm{~g})^{-1}$, cinzas 0,51 $\mathrm{g}(100 \mathrm{~g})^{-1}$, proteína $11,66 \mathrm{~g}(100 \mathrm{~g})^{-1}$, lipídios $1,35 \mathrm{~g}$ $(100 \mathrm{~g})^{-1}$, carboidratos disponíveis 75,00 g $(100 \mathrm{~g})^{-1}$ e energia de 351,00 kcal (100 g) $)^{-1}$. Comparando-se a FT com o FAT deste trabalho, percebe-se que no FAT os teores de cinzas, fibra alimentar total, proteínas e lipídios foram maiores que da FT, respectivamente $1.892,2 \%, 936,9 \%, 9,8$ e $1.418,5 \%$. Entretanto os teores de umidade e carboidratos, assim como o valor calórico foram menores no FAT, 1.215\%, 183\% e $2,7 \%$ respectivamente, o que reflete diretamente na composição química dos pães elaborados com diferentes níveis de substituição de FT por FAT. Com a elevação da substituição, os pães tendem a possuir mais fibras, proteínas, lipídios e cinzas, e menores valores calóricos, portanto mais benéficos para a saúde humana em relação aos pães tradicionais.

Os resultados médios dos parâmetros de cor do miolo ( $\mathrm{L}^{*}, \mathrm{a}^{*}$ e $\left.\mathrm{b}^{*}\right)$ dos tratamentos com diferentes níveis de substituição de farinha de trigo (FT) por farelo de arroz torrado (FAT) estão apresentados na Tabela 2.

Tabela 2. Parâmetros médios da cor do miolo de pães elaborados com diferentes níveis de substituição de farinha de trigo (FT) por farelo de arroz torrado (FAT).

\begin{tabular}{lccccc}
\hline \multirow{2}{*}{ Parâmetros de cor } & \multicolumn{5}{c}{ Tratamentos com seus níveis de substituição de FT por FAT (\%) $)^{1}$} \\
\cline { 2 - 6 } & 0,0 (controle) & 7,5 & 15,0 & 22,5 & 30,0 \\
\hline L $^{*}$ & $78,13 \pm 0,42^{\mathrm{A}}$ & $65,21 \pm 0,27^{\mathrm{B}}$ & $59,46 \pm 0,65^{\mathrm{C}}$ & $48,02 \pm 1,28^{\mathrm{D}}$ & $44,70 \pm 1,36^{\mathrm{E}}$ \\
a $^{*}$ & $1,66 \pm 0,24^{\mathrm{D}}$ & $5,82 \pm 0,06^{\mathrm{C}}$ & $7,22 \pm 0,09^{\mathrm{B}}$ & $8,83 \pm 0,21^{\mathrm{A}}$ & $8,76 \pm 1,09^{\mathrm{A}}$ \\
$\mathrm{b}^{*}$ & $15,65 \pm 0,71^{\mathrm{C}}$ & $19,45 \pm 0,25^{\mathrm{B}}$ & $21,28 \pm 0,19^{\mathrm{A}}$ & $20,73 \pm 0,34^{\mathrm{AB}}$ & $20,21 \pm 0,49^{\mathrm{AB}}$ \\
\hline
\end{tabular}

${ }^{1}$ Letras diferentes nas linhas, diferem significativamente entre si pelo teste Tukey a $5 \%$ de probabilidade.

Em relação à luminosidade $\left(\mathrm{L}^{*}\right)$ do miolo dos pães; todos os tratamentos diferiram $(\mathrm{p} \leq 0,05)$ entre si, diminuindo de acordo com a elevação do nível de substituição de FT por FAT. A L* representa quão claro ou escuro é o produto, com valores entre 0 (totalmente preto) e 100 (totalmente branco)
(WHAT..., 2007), portanto, ocorreu escurecimento gradativo do miolo dos pães com a elevação da substituição de FT por FAT. A coordenada a* diferiu $(\mathrm{p} \leq 0,05)$ entre todos os tratamentos, exceto entre os tratamentos com $22,5 \%$ e com $30,0 \%$ de substituição. A coordenada a* pode assumir valores 
de -60 a +60 , cujos extremos correspondem ao verde e ao vermelho, respectivamente (WHAT..., 2007). Assim, quanto maior o grau de substituição, mais os pães tenderam ao vermelho. A coordenada $b^{*}$ foi menor no tratamento controle e diferiu dos demais tratamentos. Houve tendência de aumento dos valores desta coordenada até o tratamento com 15,0\% de substituição de FT por FAT, e após esse nível de substituição houve diminuição não significativa $(p>0,05)$. A coordenada $b^{*}$ pode variar de -60 a +60 , cujos extremos correspondem ao azul e ao amarelo, respectivamente (WHAT..., 2007). Assim, até $15,0 \%$ de substituição de FT por FAT a intensidade da cor amarela diminuiu, mantendo-se praticamente constante a partir deste patamar.

Os escores obtidos no teste de panificação para os tratamentos com diferentes níveis de substituição de farinha de trigo (FT) por farelo de arroz torrado (FAT) estão apresentados na Tabela 3.

Tabela 3. Escores médios obtidos no teste de panificação (volume específico, características externas e internas, aroma e gosto) dos tratamentos elaborados com diferentes níveis de substituição de farinha de trigo (FT) por farelo de arroz torrado (FAT).

\begin{tabular}{|c|c|c|c|c|c|}
\hline \multirow{2}{*}{ Escore } & \multicolumn{5}{|c|}{ Tratamentos com seus níveis de substituição de FT por FAT (\%) } \\
\hline & 0,0 (controle) & 7,5 & 15,0 & 22,5 & 30,0 \\
\hline \multicolumn{6}{|l|}{ Características Externas } \\
\hline Volume específico ${ }^{1}$ & $20,00^{\mathrm{A}}$ & $16,62^{\text {в }}$ & $15,74^{\text {в }}$ & $14,10^{\mathrm{C}}$ & $12,20^{\mathrm{D}}$ \\
\hline Cor da crosta ${ }^{2}$ & $10,00^{\mathrm{A}}$ & $7,96 \mathrm{AB}$ & $7,33^{\mathrm{BC}}$ & $5,67^{\mathrm{C}}$ & $3,07^{\mathrm{D}}$ \\
\hline Caracts. da crosta ${ }^{2}$ & $5,00^{\mathrm{A}}$ & $4,00 \mathrm{AB}$ & $3,83^{\mathrm{AB}}$ & $2,42^{\mathrm{B}}$ & $2,64^{\mathrm{B}}$ \\
\hline Quebra $^{2}$ & $5,00^{\mathrm{A}}$ & $3,78^{\mathrm{AB}}$ & $3,56^{\mathrm{AB}}$ & $3,56^{\mathrm{AB}}$ & $2,44^{\mathrm{B}}$ \\
\hline Simetria $^{2}$ & $5,00^{\mathrm{A}}$ & $3,34^{\mathrm{AB}}$ & $2,89^{\mathrm{B}}$ & $2,22^{\mathrm{B}}$ & $2,00^{\mathrm{B}}$ \\
\hline \multicolumn{6}{|l|}{ Características Internas } \\
\hline Cor do miolo ${ }^{2}$ & $10,00^{\mathrm{A}}$ & $7,93 \mathrm{AB}$ & $7,41^{\text {в }}$ & $6,41 \mathrm{BC}$ & $5,00^{\mathrm{C}}$ \\
\hline Estrutura da célula do miolo ${ }^{2}$ & $10,00^{\mathrm{A}}$ & $8,72^{\mathrm{AB}}$ & $8,56^{\mathrm{AB}}$ & $7,33^{\mathrm{B}}$ & $4,83^{\mathrm{C}}$ \\
\hline Textura do miolo ${ }^{2}$ & $10,00^{\mathrm{A}}$ & $9,22^{\mathrm{AB}}$ & $9,07^{\mathrm{AB}}$ & $7,15^{\mathrm{B}}$ & $7,07^{\mathrm{B}}$ \\
\hline Aroma $^{2}$ & $10,00^{\mathrm{A}}$ & $8,96^{\mathrm{A}}$ & $9,04^{\mathrm{A}}$ & $6,44^{\text {в }}$ & $4,78^{\text {в }}$ \\
\hline Gosto $^{2}$ & $15,00^{\mathrm{A}}$ & $12,94 \mathrm{AB}$ & $12,25^{\text {в }}$ & $9,81^{\mathrm{C}}$ & $7,56^{\mathrm{D}}$ \\
\hline Escore Total $^{2}$ & $100,00^{\mathrm{A}}$ & $83,46^{\text {в }}$ & $79,68^{\mathrm{C}}$ & $65,11^{\mathrm{D}}$ & $51,59^{\mathrm{E}}$ \\
\hline
\end{tabular}

${ }^{1}$ Médias seguidas de letras diferentes nesta linha diferem entre si, a $5 \%$ de probabilidade pelo teste Tukey;

${ }^{2}$ Médias seguidas da mesma letra na mesma linha não diferem entre si, a 5\% de probabilidade pelo teste Friedman.

Os tratamentos diferiram entre si $(\mathrm{p} \leq 0,05)$ com relação ao volume específico, com exceção dos tratamentos com $7,5 \%$ e $15,0 \%$ de substituição de FT por FAT, que foram estatisticamente semelhantes $(p>0,05)$. O tratamento controle obteve o maior escore para volume específico $(20,00)$, enquanto que o menor escore para volume específico foi apresentado pelo tratamento com
$30,0 \%$ de substituição $(12,20)$, devido ao efeito da fibra, que provoca ruptura prematura das células de vapor, impedindo a retenção dos gases produzidos na fermentação. De forma geral quanto maior a substituição de FT por FAT, menor o volume específico do pão de forma resultante, como pode ser visualizado claramente na Figura 1. 


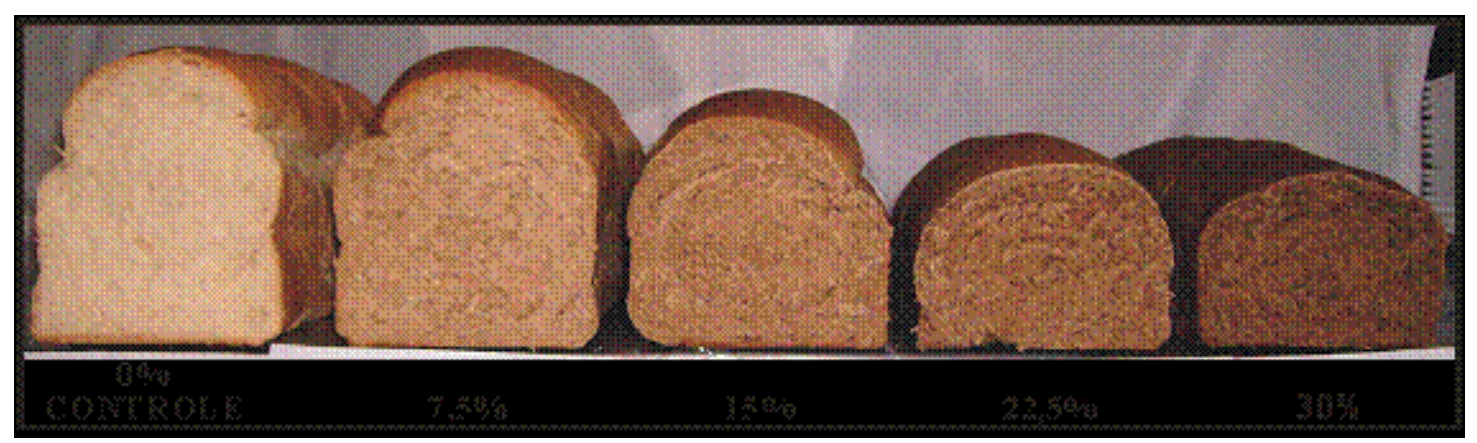

Figura 1. Foto dos pães (corte transversal) com diferentes teores de farelo de arroz torrado em substituição à farinha de trigo

Gutkoski et al. (2005) afirmaram que o volume específico representa, com bastante precisão, a variação de volume dos pães elaborados em diferentes tratamentos. O volume específico médio encontrado por estes autores para pães de forma com $100 \%$ de FT foi de $4,41 \mathrm{~cm}^{3} \mathrm{~g}^{-1}$, enquanto que o valor de $4,10 \mathrm{~cm}^{3}$. $\mathrm{g}^{-1}$ foi encontrado por Esteller e Lannes (2005), valores muito próximos ao encontrado neste trabalho $\left(4,42 \mathrm{~cm}^{3} \cdot \mathrm{g}^{-1}\right)$, pois para obter o escore para volume específico dos tratamentos multiplicaramse os valores médios de volume específico por 4,52. Segundo Esteller e Lannes (2005), o volume específico mostra claramente a relação entre o teor de sólidos e a fração de ar existente na massa assada. Pães com volumes específicos baixos (embatumados) apresentam aspecto desagradável ao consumidor, e estão associados com alto teor de umidade, falhas no batimento e cocção, pouca aeração, difícil mastigação, sabor impróprio e baixa conservação.

O tratamento controle obteve o maior escore para cor da crosta $(10,00)$, enquanto que o menor escore foi obtido pelo tratamento com $30,0 \%$ de substituição de FT por FAT $(3,07)$, assim, o escore para cor da crosta diminuiu à medida que aumentou a proporção de FAT na formulação. O tratamento controle diferiu $(\mathrm{p} \leq 0,05)$ dos demais com exceção do tratamento com 7,5\% de substituição $(p>0,05)$. Em todos os tratamentos a variação na uniformidade da cor da crosta foi pequena, provavelmente devido a um bom processo de batimento e conseqüente mistura da massa. O escore para a cor da crosta dos pães correlaciona-se diretamente com a luminosidade ( $\mathrm{L}^{*}$ ) da cor do miolo (Tabelas 2 e 3 ).

Os tratamentos com $7,5 \%$ e $15,0 \%$ de substituição de FT por FAT não diferiram $(p>0,05)$ do tratamento controle, em relação às características da crosta. Os tratamentos com maior quantidade de FAT apresentaram crosta mais dura em relação ao padrão, provavelmente em virtude destes tratamentos terem alto teor de umidade e fibras. Os tratamentos demonstraram pequena variação para a característica "borrachenta", não influenciando significativamente a composição do escore para características da crosta.

Em relação à quebra, o tratamento com $30 \%$ de substituição de FT por FAT diferiu $(\mathrm{p} \leq 0,05)$ apenas do tratamento controle. O tratamento com $30 \%$ de substituição apresentou mais rachaduras na crosta que o tratamento controle. Provavelmente, a menor quantidade de proteínas formadoras do glúten e alto teor de umidade influenciaram o quesito quebra da crosta. Isso pode ter ocorrido em decorrência de uma evaporação maior das áreas externas do pão, causando uma diferença no gradiente de umidade entre o miolo e a crosta. Com a evaporação da água, durante o resfriamento dos pães, foram geradas rachaduras para a saída do vapor proveniente do miolo que estava neste momento mais úmido que a crosta.

O tratamento com 7,5\% de substituição de FT por FAT não diferiu $(p>0,05)$ em relação à simetria 
externa do tratamento controle; os tratamentos com $22,5 \%$ e $30,0 \%$ de substituição da FT por FAT diferiram $(\mathrm{p} \leq 0,05)$ do tratamento controle em relação à estrutura da célula do miolo; e os tratamentos com 7,5\% e 15,0\% de substituição de FT por FAT não diferiram ( $\mathrm{p}>0,05)$ do tratamento controle em relação à textura do miolo. Com a elevação gradual da substituição de FT por FAT a textura tornou-se mais compacta e menos seca. A gradual substituição de FT por FAT resultou em uma compactação gradual da massa, ficando mais mole e pegajosa, ou seja, quanto maior o percentual de FAT, maior o teor de umidade retida após a cocção, em função do aumento na quantidade de fibras e da diminuição das proteínas formadoras do glúten, o que possivelmente tornou a rede de glúten mais fraca, resultando em menores retenção de gases na massa, células do miolo e volume específico, dificultando o processo manual para dar forma aos pães e exigindo maior cuidado. A absorção de água por produtos de panificação depende principalmente de dois parâmetros: o conteúdo de proteína e o conteúdo de fibras da massa. A proteína absorve seu mesmo peso em água, enquanto as fibras têm uma grande capacidade de união com a água e podem ser responsáveis pela absorção de água em até um terço do peso da massa (CAUVAIN; YOUNG, 2002).

Nabeshima et al. (2005) relataram que a alteração de cor nos pães altera diretamente sua aparência e isso pode acarretar um aumento da rejeição por parte dos consumidores. Em relação à coloração do miolo, o escore médio do tratamento controle não diferiu $(p>0,05)$ do escore do tratamento com $7,5 \%$ de substituição de FT por FAT, mas diferiu $(\mathrm{p} \leq 0,05)$ dos demais tratamentos. A coloração do miolo foi uniforme em todos os tratamentos, exceto nos tratamentos com $22,5 \%$ e $30,0 \%$ de farelo de arroz torrado, onde ocorreram pequenas e quase imperceptíveis variações na uniformidade da cor. Os resultados sugerem um escurecimento gradativo da coloração do miolo causado pela substituição gradual da FT por FAT, ou seja, quanto maior a porcentagem de farelo de arroz presente na massa, mais escuro será seu miolo, como já foi verificado por meio da luminosidade ( $\mathrm{L}^{*}$ ) (Tabela 2). Esse escurecimento é provocado pela formação de compostos escuros (melanoidinas) por meio das reações de Maillard com degradação de Strecker e a caramelização (FENNEMA, 2000), o que talvez possa ser diminuído com a otimização da temperatura e do tempo de torração do farelo de arroz, ou pela aplicação de outro tipo de tratamento térmico ao farelo de arroz, como a extrusão, que é utilizada para estabilizar o farelo de arroz no Japão e Estados Unidos (BASSINELLO, 2006).

O escore médio para aroma variou de 10,00 (tratamento controle) a 4,78 (tratamento com 30\% de substituição de FT por FAT). Os tratamentos controle, com $7,5 \%$ e $15,0 \%$ de substituição não diferiram entre si $(\mathrm{p}>0,05)$, apresentando aroma agradável pronunciado. Os tratamentos com $22,5 \%$ e $30,0 \%$ apresentaram aroma pouco pronunciado, provavelmente devido ao menor desprendimento de voláteis dos produtos após a cocção, uma vez que as cascas destes estavam mais duras e menos porosas. A quantidade de voláteis que escapam de um produto está diretamente relacionada à temperatura (a pressão de vapor aumenta com a temperatura) e à natureza dos compostos. Além disso, a volatilidade é afetada pelas condições da superfície do produto: a uma mesma temperatura, mais voláteis escapam de uma superfície macia, porosa e úmida do que de uma superfície dura, lisa e seca (FARIA; YOTSUYANAGI, 2002).

Os escores para gosto variaram entre 15,00 (tratamento controle) e 7,56 (tratamento com $30 \%$ de substituição de FT por FAT). Todos os tratamentos diferiram entre si $(\mathrm{p} \leq 0,05)$ em relação ao escore para gosto, com exceção do tratamento com 7,5\% de substituição $(12,94)$ que não diferiu $(p>0,05)$ dos tratamentos controle e com $15,0 \%$ de farelo de arroz torrado $(12,25)$. Sabe-se que o sabor (gosto mais aroma) é um fator decisivo para o consumidor na escolha do produto. O FAT adicionou um gosto "estranho" e remanescente aos pães, provavelmente em função de um excesso de torração do mesmo. 
O farelo de arroz foi torrado imediatamente após o beneficiamento do arroz, portanto este gosto "estranho" possivelmente não seja do ranço oriundo da ação de lipases nas moléculas de triacilglicerídeos, mas provavelmente da formação de polímeros escuros (melanoidinas) e de alto peso molecular derivados da reação de Maillard. Esta reação pode ser considerada como útil, quando os produtos da reação tornam o alimento mais aceitável justamente pela cor e sabor produzidos, ou prejudicial, quando pelos produtos resultantes da reação o sabor e cor do alimento não são aceitáveis (BOBBIO; BOBBIO, 2001). Portanto, a partir de $15,0 \%$ de substituição de FT por FAT, a concentração de FAT no produto o tornou do ponto de vista sensorial, mais amargo e escuro. Em outros estudos poderia ser melhorado o controle da torração para produção de FAT de melhor qualidade, ou seja, com sabor e cor mais adequados para aplicação em panificação.

As características dos pães avaliados pelos provadores treinados, somadas aos escores de volume específico, resultaram no escore total. Estes variaram entre 100,00 (tratamento controle) e 51,59 (tratamento com 30\% de substituição de FT por FAT). Todos os tratamentos diferiam $(\mathrm{p} \leq 0,05)$ entre si em relação ao escore total, no entanto, o tratamento com 7,5\% de substituição de FT por FAT não diferiu $(\mathrm{P}>0,05)$ do tratamento controle, na cor da crosta, características da crosta, quebra, simetria, cor do miolo, estrutura da célula do miolo, textura do miolo, aroma e gosto. O tratamento com 15,0\% de substituição não diferiu $(\mathrm{p} \leq 0,05)$ do tratamento controle nas características da crosta, quebra, estrutura da célula do miolo, textura do miolo e aroma. Já o tratamento com $22,5 \%$ de substituição somente não diferiu $(\mathrm{p} \leq 0,05)$ do tratamento controle em relação à quebra da crosta. Portanto, o tratamento com 7,5\% de substituição de FT por FAT foi superior, dentre os demais tratamentos com substituição parcial de FT, somando um escore total de 83,46 .

De acordo com as exigências da ANVISA (BRASIL, 2001) sobre padrões microbiológicos para alimentos, o pão de forma deve ser avaliado quanto à contagem de coliforme total e presença ou ausência de Salmonella sp em 25 g. Contudo, o INMETRO (BRASIL, 2005b) afirma que a contagem de bolores e leveduras também deve ser realizada para determinação do estado de conservação no produto fresco. Baseando-se nos resultados obtidos no teste de panificação, realizaram-se análises microbiológicas no pão de forma com 7,5\% de substituição de FT por FAT, e verificaram-se: a ausência de Salmonella "O" (A-I) em $25 \mathrm{~g}$ de pão, contagem de coliforme total menor que 10 unidades formadoras de colônias (UFC) por grama de pão (estimado), e contagem de bolores e leveduras menor que 10 unidades formadoras de colônias (UFC) por grama de pão (estimado).

De acordo com o INMETRO (BRASIL, 2005b), com relação às possíveis contaminações microbiológicas que o pão pode vir a sofrer, a mais preocupante é a que se refere à contaminação por Salmonela sp. Esta é uma bactéria patogênica, presente no intestino dos animais que, mesmo em pequenas quantidades, pode causar diarréia, vômito e febre no ser humano. O tratamento com 7,5\% de substituição de FT por FAT apresentou ausência deste microrganismo em $25 \mathrm{~g}$ de amostra, ou seja, estava dentro do padrão microbiológico exigido pela ANVISA (BRASIL, 2001).

Coliformes totais são bacilos gram negativos que fazem parte, entre outros, da microbiota residente no trato gastrointestinal dos mamíferos. A presença de coliformes totais não é um indicativo de contaminação fecal, pois este inclui bactérias não entéricas como a Serratia $s p$ e Aeromonas $s p$. No entanto sua presença serve como indicativo da qualidade higiênico-sanitária do produto (GASPAROTTO; ROCHA; GRECELLÉ, 2006). A contagem de coliforme total no tratamento com $7,5 \%$ de substituição de FT por FAT foi menor que

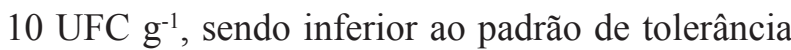
máxima (100 UFC $\mathrm{g}^{-1}$ ) estipulado pela ANVISA (BRASIL, 2001). 
A contaminação por bolores, vulgarmente conhecidos como mofo, está relacionada, principalmente, a problemas de conservação no armazenamento do produto. Contudo, a contaminação por bolores não representa risco para a saúde humana, principalmente, porque o consumidor dificilmente ingerirá um produto contaminado por este tipo de fungo, quando estes estão visíveis a olho nu, além de deixar cheiro e sabor característicos no alimento (BRASIL, 2005b). O tratamento com 7,5\% de substituição de FT por FAT apresentou contagem de bolores e leveduras menor que $10 \mathrm{UFC} \mathrm{g}^{-1}$, bem inferior ao padrão máximo de tolerância $(5.000$ UFC $\mathrm{g}^{-1}$ ) determinado pelo INMETRO (BRASIL, 2005b). Segundo Franco e Landgraf (2003), baixas contagens de bolores e leveduras são normais em alimentos frescos ou congelados. Tendo em vista os resultados obtidos nas análises microbiológicas, o produto está de acordo com a legislação vigente, portanto, em condições sanitárias satisfatórias, de acordo com a Resolução RDC nº . 12, da Anvisa de 2 de janeiro de 2001 (BRASIL, 2001), indicando que o produto do ponto de vista microbiológico pode ser perfeitamente empregado para o consumo humano.

\section{Conclusões}

O farelo de arroz torrado é um alimento rico em fibras, principalmente insolúveis, lipídios, proteínas e cinzas.

Os pães de forma tornam-se mais escuros, com crosta mais dura e com menor volume específico com a elevação do teor de farelo de arroz torrado na formulação.

O tratamento com 7,5\% de farelo de arroz torrado apresenta características próximas às do tratamento sem farelo de arroz torrado; apresentando qualidade sanitária adequada em relação aos padrões microbiológicos exigidos pela legislação brasileira; possuindo condições satisfatórias para comercialização e consumo humano.

\section{Referências}

ALENCAR, M. L. C. B.; ALVARENGA, M. G. Farelo de arroz (I): composição química e seu potencial como alimento. Arquivos de Biologia e Tecnologia, Belo Horizonte, v. 34, n. 1, p. 95-108, 1991.

ASSOCIATION OF OFFICIAL AGRICULTURAL CHEMISTS INTERNATIONAL - AOAC. Official methods of analysis of AOAC International. 16.ed. Maryland: AOAC International, 1997.

BARBER, S.; BARBER, C. B.; MARTÍNEZ, J. Proteínas del salvado de arroz. II. Valor potencial de las fracciones de salvado de arroz como ingredientes de alimentos protéicos. Revista de Agroquímica y Tecnologia de Alimentos, Valencia, v. 21, n. 2, p. 247-258, 1981.

BASSINELLO, P. Z. Farelo de arroz, um alimento saudável. Boletim Pecuário. Disponível em: <http:// www.boletimpecuario.com.br/artigos/showartigo. php? arquivo $=$ artigo 936. txt\&tudo $=$ sim $>$. Acesso em: 25 ago. 2006.

BOBBIO, P. A.; BOBBIO, F. O. Química do processamento de alimentos. 3.ed. São Paulo: Varela, 2001.

BRASIL. Ministério da Agricultura Pecuária e Abastecimento. Instrução Normativa $n^{\circ} 62$, de 26 de agosto de 2003. Métodos analíticos oficiais para análises microbiológicas para controle de produtos de origem animal e água. Disponível em: $<\mathrm{http}$ ://oc4j.agricultura. gov.br/agrolegis/do/consultaLei?op=viewTextual\&codig $\mathrm{o}=2851>$. Acesso em: 28 jan. 2007.

BRASIL. Ministério da Saúde. Agência Nacional de Vigilância Sanitária. Resolução - RDC n ${ }^{\circ} 12$, de 2 de janeiro de 2001. Aprova "regulamento técnico sobre padrões microbiológicos para alimentos". Diário Oficial [da] República Federativa do Brasil, Brasília, 2 janeiro 2001. Disponível em: <http://e-legis.bvs.br/leisref/ public/showAct.php?id=144>. Acesso em: 29 dez. 2006.

BRASIL. Ministério da Saúde. Agência Nacional de Vigilância Sanitária. Métodos físico-químicos para análise de alimentos. Brasília: Ministério da Saúde; Instituto Adolfo Lutz, 2005a.

BRASIL. Ministério do Desenvolvimento, Indústria e Comércio Exterior, Instituto Nacional de Metrologia, Normalização e Qualidade Industrial. Pão de forma ou para sanduíche. 2005b. Disponível em: <http://www. inmetro.gov.br/consumidor/produtos/paoforma.asp $>$. Acesso em: 9 jan. 2007.

BRUNE, M.; ROSSANDER-HULTEN, L.; HALLBERG, L.; GLEERUP, A., SANDBERG, A. Iron absorption from bread in humans: inhibition effects of cereal fiber, 
phytate and inositol phosphates with different numbers of phosphate groups. Journal of Nutrition, Philadelphia, v. 122, n. 3, p. 442-449, 1992.

CARVALHO, C. W. P. Uso de farelo de arroz na produção de biscoito tipo amanteigado. 1995. Dissertação. (Mestrado em Ciência e Tecnologia de Alimentos) Universidade Federal de Viçosa, Viçosa.

CARVALHO, J. L. V.; BASSINELLO, P. Z. Aproveitamento Industrial. In: SANTOS, A. B.; STONE, L. F.; VIEIRA, N. R. (Ed.). A cultura do arroz no Brasil. 2.ed. Santo Antônio de Goiás: Embrapa Arroz e Feijão, 2006. p. 1007-1041.

CASTRO, E. M.; VIERA, N. R. A.; RABELO, R. R.; SILVA, S. A. Qualidade de grãos em arroz. Santo Antônio de Goiás: Embrapa Arroz e Feijão, 1999.

CAUVAIN, S. P.; YOUNG, L. S. Fabricación de pan. Zaragoza: Editorial Acribia, 2002.

DIAS, L. C. G. D.; REYES, F.; CAMARGO, J. L. V.; RODRIGUES, M. A. M. Conteúdo de celulose, hemicelulose e lignina no farelo de arroz fresco. Revista Nutrição PUCCAMP, Campinas, v. 7, n. 1, p. 62-70, 1994.

ESTELLER, M. S.; LANNES, S. C. S. Parâmetros complementares para fixação de identidade e qualidade de produtos panificados. Ciência e Tecnologia de Alimentos, Campinas, v. 25, n. 4, p. 802-806, 2005.

FARIA, E. V.; YOTSUYANAGI, K. Técnicas de analise sensorial. Campinas: ITAL/LAFISE, 2002.

FENNEMA, O. R. Química de los alimentos. Zaragoza: Acribia, 2000.

FRANCO, B. D. G. M.; LANDGRAF, M. Microbiologia dos alimentos. São Paulo: Atheneu, 2003.

GASPAROTTO, P. H. G.; ROCHA, C. S.; GRECELLÉ, C. B. Z. Quantificação de coliformes totais e fecais pela técnica do NMP em amostras de água do município de Ji-Paraná. Ciência \& Consciência, Ji-Paraná, v. 2, 2006. Disponível em: <http://www.revista.ulbrajp.edu.br/seer/ inicia/ojs/viewissue.php>. Acesso em: 9 jan. 2007.

GUTKOSKI, L. C.; BREHM, C. M.; SANTOS, E.; MEZZOMO, N. Efeito de ingredientes na qualidade da massa de pão de forma congelada não fermentada durante o armazenamento. Ciência e Tecnologia de Alimentos, Campinas, v. 25, n. 3, p. 460-467, 2005.

HAN, O.; FAILA, M. L.; HILL, A. D.; MORRIS, E. R.; SMITH JÚNIOR, J. C. Inositol phosphates inhibit uptake and trans-port of iron and zinc by human intestinal cell line. Journal of Nutrition, Philadelphia, v. 124, n. 4, p. 580-587, 1994.
HOFFPAUER, D. W. New applications for whole rice bran. Cereal Foods World, Minneapolis, v. 50, n. 4, p. 173-174, 2005.

LÖNNERDAL, B.; SANDBERG, A. S.; SANDSTRÖM, B.; KUNZ, C. J. Inhibitory effect of phytic acid and other inositol phosphates on zinc and calcium absorption. Journal of Nutrition, Philadelphia, v. 199, n. 2, p. 211214, 1989.

MARTINEZ-DOMINGUEZ, B.; GOMES, M. I.; LEÓN, F. R. Ácido fítico: aspectos nutricionales e implicaciones analíticas. Archivos Latinoamericanos de Nutricion, Caracas, v. 52, n. 3, p. 219-231, 2002.

NABESHIMA, E. H.; ORMENESE, R. C. S. C.; MONTENEGRO, F. M.; TODA, E.; SADAHIRA, M. S. Propriedades tecnológicas e sensoriais de pães fortificados com ferro. Ciência e Tecnologia de Alimentos, Campinas, v. 25 , n. 3 , p. $506-511.2005$.

PEREIRA, J. A. Cultura de Arroz no Brasil: subsídios para a sua história. Terezina: Embrapa Meio-Norte, 2002.

PIMENTEL-GOMES, F. Curso de estatística experimental. 14.ed. Piracicaba: Degaspari, 2000.

RICKARD, S.; THOMPSON, L. Interactions and biological effects of phytic acid. In: SHAIDI, F. (Ed.). Antinutrients and phytochemicals in food. Washington: American Chemical Society, 1997. p. 294-312.

SAMPAIO, F. S.; MEDEIROS, M. C. Dinâmica de mercado e acumulação: os complexos agroindustriais do arroz e da laranja. Disponível em: <http://www.ie.ufu. br/ix_enep_mesas/Mesa $\% 2027 \% 20-\% 20$ Economia $\% 20$ agr\%C3\%A1ria\%20e \%20do\%20meio\%20ambiente $\% 20$ II/Din $\%$ C3\%A2mica $\% 20$ de $\% 20$ Mercado $\% 20$ e $\% 20$ Acumula\%C3\%A7\%C3\%A3o.pdf>. Acesso em: 27 ago. 2006.

SAUNDERS, R. M. The properties of rice bran as a foodstuff. Cereal Food World, Minneapolis, v. 35, n. 7, p. 632-636, 1990.

SHAHIDI, F. Beneficial health effects and drawbacks of antinutrients. In: SHAHIDI, F (Ed.). Antinutrients and Phytochemicals in Food. Washington: American Chemical Society, 1997. p. 1-9.

SILVA, M. A.; SANCHES, C.; AMANTE, E. R. Prevention of hydrolytic rancidity in rice bran. Journal of Food Engineering, Essex, v. 75, n. 4, p. 487-491, 2006.

SOARES JÚNIOR, M. S.; OLIVEIRA, W. M.; CALIARI, M.; VERA, R. Otimização da formulação de pães de forma preparados com diferentes proporções de farinha 
de trigo, fécula de mandioca e okara. Boletim Centro de Pesquisa e de Processamento de Alimentos, Curitiba, v. 24, n. 1, p. 221-248, 2006.

UNIVERSIDADE DE SÃO PAULO - USP. TBCAUSP: Tabela brasileira de composição de alimentos da Universidade de São Paulo. 2005. Disponível em: < http:// www.fcf.usp.br/tabela>. Acesso em: 20 jan. 2007.

VIEIRA, N. R. A.; SANTOS, A. B.; SANT'ANA, E. P. A Cultura do Arroz no Brasil. Santo Antônio de Goiás: Embrapa Arroz e Feijão, 1999.
VILAS BOAS, E. V. B. Alimentos e nutrientes. Lavras: UFLA/FAEPE, 1999.

WHAT is CIE 1976 ( $\mathrm{L}^{*} \mathrm{a}^{*} \mathrm{~b}$ ) colour space? Disponível em: <http://www.colourware.co.uk/cpfaq/q3-21.htm>. Acesso em: 2 jul. 2007.

WILSON, E. D.; SANTOS, A. C.; VIEIRA, E. C. Energia. In: DUTRA-DE-OLIVEIRA, J. E.; SANTOS, A. C.; WILSON, E. D. (Org.). Nutrição básica. São Paulo: Savier, 1982. 
